\title{
International Crises of Legitimacy
}

\author{
Christian Reus-Smit \\ Department of International Relations, Research School of Pacific and Asian Studies, Australian \\ National University, Canberra, ACT 0200, Australia. \\ E-mail: Christian.Reus-Smit@anu.edu.au
}

\begin{abstract}
What is an international crisis of legitimacy? And how does one resolve such crises? This article addresses these conceptual issues, laying the theoretical foundations for the special issue as a whole. An actor or institution experiences a crisis of legitimacy, it is argued, when the level of social recognition that its identity, interests, practices, norms, or procedures are rightful declines to the point where it must either adapt (by reconstituting or recalibrating the social bases of its legitimacy, or by investing more heavily in material practices of coercion or bribery) or face disempowerment. International crises of legitimacy can be resolved only through recalibration, which necessarily involves the communicative reconciliation of the actor's or institution's social identity, interests, practices, norms, or procedures, with the normative expectations of other actors within its realm of political action.
\end{abstract}

International Politics (2007) 44, 157-174. doi:10.1057/palgrave.ip.8800182

Keywords: legitimacy; power; crisis of legitimacy; resolution

\section{Introduction}

For all of the talk of crises of legitimacy in contemporary world politics, there is surprisingly little reflection on what such crises are. And despite International Relations scholars' newfound interest in questions of legitimacy, little attention has been given to the concept of international crises of legitimacy. What does it mean to speak of an international crisis of legitimacy, and how do we know one when we see one? This failure to grapple with the nature of legitimation crises has led to a concomitant failure to address the issue of crisis resolution. What does it mean to resolve an international crisis of legitimacy? Is it sufficient to suppress dissent or buy compliance, or does resolution demand something more?

This article addresses these conceptual issues, laying the theoretical foundations for the following, more empirical chapters. Part One is devoted to the concept of legitimacy, and to the task of differentiating it from associated concepts, such as legitimate, legitimation, and legitimacy claim, and from other ethical values, principally order, justice, legality, and morality. Part Two explores the critical relationship between power and legitimacy, arguing 
that legitimacy is best conceived as a source of power, not a veil to power, as it is commonly described. Part Three confronts the central issue of what constitutes an international crisis of legitimacy. I suggest that an actor or an institution can be said to experience a crisis of legitimacy when the level of social recognition that its identity, interests, practices, norms, or procedures are rightful declines to the point where the actor or institution must either adapt (by reconstituting the social bases of its legitimacy, or by investing more heavily in material practices of coercion or bribery) or face disempowerment. Part Four explains what we mean by the 'resolution' of international crises of legitimacy.

\section{Legitimacy}

We use the language of legitimacy in a wide range of social situations. We describe it as legitimate for parents to ask after their child's progress at school, and legitimate for a tradesperson to ask for payment after work is done. In these contexts, the language of legitimacy is employed to describe not just the capacity to act, but the right or entitlement to act. Mark Suchman captures this when he defines legitimacy as 'a generalized perception or assumption that the actions of an entity are desirable, proper, appropriate within some socially constructed system of norms, values, beliefs, and definitions' (Suchman, 1995, 574). It is in the political realm, though, that the original meaning of the term lies, deriving as it does from the quintessential politico-legal term 'legislate'. Here legitimacy is generally taken to mean the right to rule, or the right to govern (Coicaud, 2002, 10). The Oxford English Dictionary (OED) defines 'to rule' as to be 'in control', and 'right' as 'justification, fair claim, being entitled to privilege or immunity, thing one is entitled to'. In the political arena, broadly conceived, legitimacy thus refers to an entitlement to control, which generally means an entitlement to issue authoritative commands that require compliance from those subject to them. An actor can be said to command legitimacy, therefore, when its decisions and actions (and I would contend identities and interests) are socially sanctioned.

Actors with clear agential characteristics are not the only entities to which the language of legitimacy can be applied - institutions and social orders can also be described as legitimate or illegitimate. To the extent that institutions have organizational structures, such as the United Nations or the World Trade Organization (WTO), describing their legitimacy in terms of a right to act is partially correct - these institutions, by virtue of their organizational capacities, do indeed 'act'. There is a second, more fundamental sense, however, in which we describe such entities as legitimate or illegitimate. Institutions are commonly defined as stable sets of norms, rules, and principles 
that shape social relations by constituting actors as knowledgeable social agents and by regulating their behaviour (Reus-Smit, 1999, 12-13). The actions of organizationally developed institutions can be described as legitimate or illegitimate, but so can the norms, rules, and principles that undergird and license these actions. Institutions without developed organizational structures can only be described as legitimate or illegitimate in this latter sense - it is not their right to act that is in question, but the rightfulness of the norms, rules, and principles that constitute them. When we speak of an institution commanding legitimacy, therefore, we are saying that there is a generalized perception that its normative precepts are rightful, ${ }^{1}$ that they warrant respect and compliance for more than self-interested reasons, for reasons of their normative standing. This is true of domestic and international institutions, and also of different kinds of international institutions: regimes, like the WTO; fundamental institutions, such as international law and multilateralism; and constitutive institutions, of which sovereignty is the principal.

Legitimacy is a social concept in the deepest sense - it describes a phenomenon that is inherently social. As soon as we say that an actor has a 'right' to act, 'right' to rule, or a 'right' to govern, we are saying more than they have the capacity to do so. Rights are socially ordained, and an actor has a right to act, rule, or govern only if it is socially sanctioned. Similarly, when we say that an institution is rightful, and hence legitimate, we are saying that its norms, rules, and principles are socially endorsed. As Suchman's definition stresses, legitimacy is inextricably dependent upon social perception and recognition. Auto-legitimation is an oxymoron - an actor can jump up and down, declaring loudly that his or her actions are legitimate, but if nobody accepts this, then they are not correctly described as such, even if he or she is making a legitimacy claim. 'The very idea of a right presupposes the existence of a community. In a world in which but a single person lived, right would have no room to exist' (Coicaud, 2002, 11).

Legitimacy is a quality that society ascribes to an actor's identity, interests, or practices, or to an institution's norms, rules, and principles. When society ordains this quality, such things are said to enjoy or command legitimacy. When legitimacy is ascribed to an actor or institution, we describe it as legitimate. Political actors are constantly seeking legitimacy for themselves or their preferred institutions and in doing so they engage in practices of legitimation. Because legitimation is a normative process, it is characterized by actors seeking to justify their identities, interests, practices, or institutional designs. These justifications constitute legitimacy claims. Actors making legitimacy claims is the lifeblood of the politics of legitimation, and such politics is essential to the cultivation and maintenance of an actor's or institution's legitimacy. An actor making a legitimacy claim does not mean, however, that she commands legitimacy - only when such claims are 
recognized as rightful within the political realm in which the actor seeks to act, or the institution is intended to have jurisdiction, would this be the case. Legitimacy claims denote the politics of legitimation, not necessarily legitimacy (Clark, 2005, 2-3).

Because of its inherently social nature, legitimacy should not be conflated with other social values. Politicians, journalists, and scholars frequently use the language of legitimacy interchangeably with the language of rationality, justice, legality, and morality. But while legitimacy claims may draw on such values in the politics of legitimation, legitimacy is not their synonym. An actor might plausibly describe his or her actions as rational if they are a logical means to realize their interests within prevailing environmental constraints, and the veracity of this claim does not depend upon it being socially recognized (although what an actor decides is a 'logical means' may well depend upon intersubjective understandings about rightful action). An actor might reasonably describe his or her actions as legal if they conform to a relevant body of legal doctrine, and widespread hostility to these actions would not necessarily invalidate this claim. A dictator could claim that the jailing of her political opponents was perfectly legal under her emergency laws, and the population being in uproar would not itself disprove this. An actor might plausibly describe his or her actions as just, regardless of the level of social endorsement. If the actor adopted a narrowly utilitarian conception of justice, and was able to demonstrate empirically that the actions would bring the greatest good to the greatest number, this claim would not be inherently implausible, even if it were vigorously contested socially. And an actor might reasonably characterize his or her actions as moral if they were consistent with their favoured moral philosophy. Other social actors might contest these claims, saying that the actions in question violate their preferred moral values. But this does not invalidate the initial claim; it merely demonstrates that an action can be moral from one perspective and immoral from another. The critical thing that differentiates legitimacy from these values is the necessity of social recognition. No action can be coherently described as legitimate if it is not socially recognized as rightful.

\section{Power and Legitimacy}

It is commonplace in the study of international relations to treat power and legitimacy as distinct social phenomena, to define power in terms of material might and legitimacy as a valuable addendum to power, so defined. This is captured in the notion of 'naked power', and the idea that legitimacy veils such power, making it socially acceptable. As Inis Claude Jr put it, 'Among statesmen, the lovers of naked power are far less typical than those who aspire 
to clothe themselves in the mantle of legitimate authority; emperors may be nude, but they do not like to be so, to think themselves so, or to be so regarded' (Claude, 1966, 368). Power, from this perspective, is understood in material terms, as consisting in, or flowing from, guns, money, technology, geography, and so on. Legitimacy is acknowledged to be a social phenomenon, grounded in intersubjective meanings and values, and constructed through social communication. But instead of being seen as a source of power, it is treated as a veil or mantle that disguises the true nature of power, making it appear more palatable, less offensive or brutal than it might otherwise. The true nature of power - its material essence - always lies behind, however. And legitimacy may obscure this, but it does not condition or constitute power.

This separation of power and legitimacy is belied by the very idea of a "crisis of legitimacy', an idea that implies a far more intimate relation between the two. When we speak of a crisis of legitimacy, we speak of a crisis engendered by insufficient or failing legitimacy, by a deficit of social recognition or entitlement. But what is this a crisis in? The answer, of course, is that it is a crisis in an actor's ability to achieve their ends, or an institution's capacity to enlist norm-compliant behaviour. In other words, it is a crisis in an actor's or institution's power. The idea of a crisis of legitimacy thus implies that insufficient or failing legitimacy is corrosive of power, not just exposing of power. And, in the reverse, that robust legitimacy is constitutive of power, not merely a veil.

An exploration of international crises of legitimacy demands a richer understanding of power and legitimacy than the common bifurcation. The starting point for such an understanding must be a reconsideration of the concept of power itself. We are accustomed in International Relations to think of power in terms of resources, in terms of material things that states possess that can be quantified and ranked to produce a league table of relative state 'power'. Kenneth Waltz's emphasis on the distribution of capabilities is archetypical of this tendency. His use of the term 'capabilities' is interesting, though. For Waltz, capabilities connote resources. But this is not the conventional understanding. Capability generally means 'practical capacity', not resources. Resources may contribute to such capacity, but the relationship may be complex and attenuated. Waltz lists 'population and territory, resource endowment, economic capability, military strength, political stability, and competence' as prime state capabilities (Waltz, 1979, 131). Five of these are resources only, with an unproblematic connection to practical capacity assumed. And two - economic capability and military strength — imply practical capacity, but this is contradicted by Waltz's insistence that ranking states 'does not require predicting their success in war or in other endeavors' (Waltz, 1979, 131). In other words, it does not require predicting their practical capacity. For Waltz, therefore, the equation is that capabilities equal resources, 
and resources equal power, an equation assumed in much of the literature on international relations.

Instead of assuming that resources equate to power, it is analytically preferable to separate the two conceptually, and to study their changing relation empirically. My own preference is to take the notion of capability (or practical capacity) seriously, as essential to any notion of power. When we say that an actor is powerful, we are saying more than they command substantial resources; we are saying that they have the capacity to realize their objectives, to translate the resources they command into intended outcomes. And when we say that an institution is powerful, we are not just cataloguing its constitutive norms, rules, or decision-making procedures, we are pointing to its transformative capacity, its ability to engender behavioural change in those within its jurisdiction. As Max Weber explained, power is 'the probability that one actor within a social relationship will be in a position to carry out his own will despite resistance, regardless of the basis on which this probability exists' (Weber 1957, 152). Or as Joseph Nye put it more recently, power is 'the ability to effect the outcomes you want, and if necessary, to change the behavior of others to make this happen' (Nye, 2002, 4).

Power, so understood, can have multiple sources, material and non-material. Few would deny that material resources, such as guns and money, are relevant to power, even if they are not determining. States with agricultural instead of industrial economies, nuclear arsenals instead of purely conventional militaries, or landlocked instead of coastal territories face different constraints and opportunities. These material factors do not, however, exhaust the sources of power. Power is constituted in profound ways by non-material factors as well, including ideas, beliefs, norms, and rules, and by the institutional structures and communicative processes that embed and mobilize them. Furthermore, these factors do not simply stand alongside the material sources of power, as so many additional chess pieces on a board. In addition to the independent effects they have on power - as the idea of divine right had in constituting the power of absolute monarchs - they also condition the impact that material factors have on power. Brute material factors may define the 'outer limits of feasibility' (Wendt, 1999, 111), but their social meaning, and hence their political import, is determined by the intersubjective ideas, beliefs, norms, and rule that actors attribute to them. In Marshall Sahlins's words, 'material effects depend on their cultural encompassment' (Sahlins, 1976, 194).

The politics of legitimacy is a crucial part of the 'cultural encompassment' that conditions the nature and exercise of power. As we have seen, legitimacy is a quality that actors ascribe to another actor's identity, interests, or practices, or to an institution's norms, rules, and principles. This process of ascription is always norm-referential. When actors make judgements about the legitimacy of another actor's identity, interests, or actions, they necessarily do so with 
reference to social norms that specify how that kind of actor, in that kind of situation, ought to project itself, define its preferences, and translate those preferences into actions. Even when an actor's legitimacy is contested, when other actors are divided over its rightfulness, the contestation is almost always over what constitute the operative norms, and over how they should be interpreted. Ascribing legitimacy is also inextricably linked to, and dependent upon, social communication. Actors establish their legitimacy, and the legitimacy of their actions, through the rhetorical construction of self-images and the public justification of priorities and practices, and other actors contest or endorse these representations through similar rhetorical processes. Establishing and maintaining legitimacy is thus a discursive phenomenon, and the nature of this discursive phenomenon will depend heavily upon the prevailing architecture of social norms, upon the cultural mores that govern appropriate forms of rhetoric, argument, and justification, and upon available technologies of communication (Reus-Smit, 1999, 77-84; Bukovansky, 2002, 3).

What, precisely, does legitimacy contribute to an actor's or institution's power? Let us consider the null case of an actor seeking to rule without right. That is, an actor who seeks to make decisions that demand the compliance of others without the social recognition that such decision-making power is rightful. To attain compliance, such an actor must rely on the pure self-interest of other actors: their desire to avoid harm, their susceptibility to bribery, and their calculations that their interests might be furthered. This means that the power-aspirant must rule through the maintenance of a regime of credible threats, the constant provision of largesse in return for compliance, and the pandering to sectional interests. All of these things are costly and unstable bases of power, as threat regimes are vulnerable to shifts in the balance of relative material might, those open to bribery need repeated payment to remain loyal, and the preferences of other actors are subject to change. In addition to these costs and vagaries, our power-aspirant must forego the benefits of nonself-interested, voluntary compliance. This is the compliance that actors give when they believe a rule, decision, or command is rightful, even if it contradicts their narrow self-interests. Very often compliance rests on the coincidence of duty or obligation and self-interest, but often it does not - in our daily lives we frequently (though not always) make the hard choice of acting in a way that we know is right rather than in a way that would serve our immediate selfinterests. Tapping into this resource of non-self-interested, voluntary compliance is what our power-aspirant foregoes.

Actors who command legitimacy are empowered in three crucial ways, all of which relate to the wellspring of voluntarism that they can tap into. First, they can draw on the active support of other actors who do more than simply comply with their decisions, actively investing their resources and energies in the project that lies behind them. Second, they can draw on simple compliance, 
the behaviour of other actors in accordance with their rules, decisions, or commands, but no more or no less. And, finally, they can benefit from low levels of opposition, which reduces the costs of coercion and bribery.

In positing a relationship between power and legitimacy, or between practical capacity and social sanction, one crucial question remains - in which social constituency must an actor command legitimacy for his or her power to be augmented? Here it is useful to conscript two further concepts: the realm of political action, and the social constituency of legitimation. The question of which constituency an actor must establish legitimacy in can be answered only with reference to the political realm in which he or she seeks to act. For a small town mayor, this will be the town itself and any wider authorities whose opinion is relevant to the pursuit of mayoral objectives. For the Bush administration, whose ambitions are global, the operative realm of political action is both American domestic society and the wider international system. Where one needs legitimacy will depend, therefore, upon where one seeks to act, and the relevant constituency will be determined by that realm of political action. We know all too well, though, that a disjuncture often exists between an actor's realm of political action and the community in which they actually command legitimacy, deliberately or otherwise. I shall term this community 'the social constituency of legitimation', the actual social grouping in which legitimacy is sought, ordained, or both. These constituencies can be domestic, international, or transnational; they can constitute broad cross-sections of national societies (or of international society), or they can be sectoral or issuebased. The crucial thing is that for an actor to attain a comprehensive legitimacy dividend, its realm of political action (which itself may be geographic or sectoral) and its social constituency of legitimation need to be coextensive, or at least approximate one another.

Frequently this is not the case, however. Often an actor's constituency of legitimation is considerably more circumscribed than their chosen realm of political action. The Bush administration has enjoyed legitimacy in a social constituency that comprises, domestically, the Christian right, Southern conservatives, large sectors of corporate America, and enough other Americans to secure at least one unambiguous presidential election and a congressional majority. Internationally, it has commanded legitimacy among a small number of staunch allies and, presumably, a large sector of the global corporate world. Yet in large sectors of international and world society, the administration and its practices are seen as profoundly illegitimate. And it is this disjuncture between its social constituency of legitimation and its chosen realm of political action that underlies the administration's current international crisis of legitimacy.

Before proceeding, it is worth dispensing with the common assumption that material might breeds its own legitimacy. This is the idea that other actors will 
ordain the identity, interests, and actions of a preponderant state, for example, with legitimacy simply by virtue of its material preponderance. Another version is the idea that demonstrations of material might — through the exercise of force, for example - augment a preponderant state's legitimacy. There is no doubt that material might, and demonstrations thereof, can inspire a range of emotional and normative responses from other actors, such as awe and excitement, or fear and anxiety. But material might contributes to a preponderant state's legitimacy only if other actors make two crucial judgements: that such might is possessed and exercised by a state whose identity and interests are compatible with accepted norms of legitimate statehood and international leadership, and that the state in question will use its might in a manner consistent with ascendant norms of rightful state action. Material might, therefore, is never sufficient, in and of itself, to attract or sustain legitimacy. Judgements of legitimacy within international society are always made with reference to the normative architecture of that society, and the relationship between a preponderant state's identity, interests, actions, and material might, on the one hand, and international norms, on the other, is necessarily mediated by processes of social communication and argument.

A similar response can be made to the proposition that efficacy breeds legitimacy. For instance, it is often claimed that America's success or failure in Iraq will be the final arbiter of the war's legitimacy or illegitimacy. If Washington succeeds, then the current aura of illegitimacy will fade, replaced by a sense that the war was rightful after all. But even if this turns out to be the case, judgements about the efficacy of actions are not made in a vacuum. An action is not judged efficacious if it produces any outcome; it is judged as such only if it delivers the promised outcomes (or some persuasive alternative), and only if these outcomes are themselves considered rightful. If Washington succeeds in establishing order through a functioning democracy, judgements as to the war's legitimacy will be different from if it succeeds in securing order only through the installation of another Saddam-like autocracy. For efficacy to deliver legitimacy, therefore, an actor must be effective in delivering outcomes deemed appropriate, and judgements about the appropriateness of effectively delivered outcomes are, like those of material might, made in relation to prevailing social norms.

\section{International Crises of Legitimacy}

We have now laid the groundwork for confronting the central problematic of this article - what constitutes an international crisis of legitimacy? Let us first dispense with the 'international' aspect of the concept. What do we mean when we delimit our inquiries to international crises of legitimacy? Two things are 
clear. We are not adopting a narrow 'Waltzian' conception of the international, such as external relations among hermetically sealed sovereign states. The very notion of an international crisis of legitimacy militates against this, as such crises are often rooted in social forces and processes that exist at domestic or transnational levels. At the same time, though, we are excluding from our analyses crises of legitimacy that are exclusively domestic in their origins and effects. When in 1975 Australia's Governor General Sir John Kerr dismissed the government of Gough Whitlam, the office of the Governor General suffered a severe crisis of legitimacy, from which it has never fully recovered. But one would struggle to find any notable international aspects (even if some credit its origins to the meddling of foreign powers, notably the CIA). In this special issue we use the term 'international' to refer to that amorphous social realm that encompasses the complex array of political relations among states and non-state actors (and the institutions they construct and maintain) that transcend and constitute the territorial boundaries of sovereign states. An international crisis of legitimacy is thus one that afflicts these actors, their institutions, or the political orders they constitute.

All of this leads to the question of what constitutes a crisis of legitimacy, international or otherwise. An actor or institution may suffer a decline in legitimacy, or may have trouble establishing robust legitimacy in the first place, but when does this decline or failure constitute a 'crisis'? The $O E D$ defines a 'crisis' as 'a turning point in the course of anything; decisive or crucial time, stage, or event'. In its early usage, crisis was a predominantly medical term, used to describe that critical point in the course of a disease when the patient would either survive or die. The rhetorical force of crisis language thus depends on two things. It depends, first, on terminal endings, such as death, collapse, demise, disempowerment, or decline into irrelevance, being real, even immanent possibilities that only immediate action can avert. But if 'crisis' is to be more than a synonym for such endings it must also imply the imperative, and hence the possibility, of remedial action. Furthermore, we know historically that phenomena we readily see as afflicted by crises of legitimacy have been ameliorated by artful political practices. As Mlada Bukovansky observes, 'the Concert of Europe shows that legitimacy contests may in the end be managed by political leaders, if those leaders are able to learn the relevant lessons of the day and cobble together an order that takes into account both traditional claims and those of newly empowered (and/or newly dissatisfied) sociopolitical actors' $(2002,233)$. For the purposes of this study, therefore, crises will be defined as critical turning points in which the imperative to adapt is heightened by the immanent possibility of death, collapse, demise, disempowerment, or decline into irrelevance.

What kind of crisis, then, is a crisis of legitimacy? When we say that an actor or institution is suffering a crisis of legitimacy, we are saying that the decline in 
its legitimacy, or its failure to cultivate sufficient legitimacy, has reached a critical turning point. Because legitimacy is but one source of social power, the critical turning point is not necessarily, or immediately, marked by a precipitous decline in an actor's or an institution's political capacity. Decline can be averted by either of two forms of adaptation. An actor or institution can reconstitute the social bases of its legitimacy, or it can draw on material sources of power to compensate for its declining legitimacy. Both of these responses are demanding. To reconstitute its legitimacy, an actor or institution must, first, recalibrate the relationship between its social identity, purposes, and practices, and the prevailing social norms that define the parameters of rightful agency and action; and, second, realign its realm of political action with its social constituency of legitimation. To substitute material sources of power for legitimacy, an actor or institution must possess these sources in the first place and then be willing to incur the costs and vagaries associated with rule by coercion and bribery. A crisis of legitimacy, therefore, can be defined as that critical turning point when decline in an actor's or institution's legitimacy forces adaptation (through re-legitimation or material inducement) or disempowerment. $^{2}$

The most sustained theoretical consideration of crises of legitimacy is found in the post-Marxist writings of Jurgen Habermas, and it is ironic that a concept so grounded in critical social theory should have become so central to contemporary discourse on international relations. Here is not the place for a sustained exegesis of Habermas's thought on the topic. It is worth noting, however, several similarities and differences between his conception and that advanced here. For Habermas, as with our contributors, political power is intimately connected to, and dependent upon, legitimacy. Referring to state power in particular, he writes that 'governmental activity can find a necessary limit only in available legitimations' (Habermas, 1973, 69). Habermas also insists that legitimacy is ultimately grounded in the intersubjective meanings, normative structures, and social institutions that facilitate social integration. Indeed, a 'legitimation deficit means that it is not possible by administrative means to maintain or establish effective normative structures to the extent required' $(1973,47)$. So central are these ideas to Habermas's conception of social systemic crisis, that he defines crises largely in terms of problems of legitimation. 'Disturbances of system integration', he writes, 'endanger continued existence [of a social system] to the extent that social integration is at stake, that is, when the consensual foundations of normative structures are so much impaired that the society becomes anomic' $(1973,3)$.

Despite these similarities with the approach advanced here, readers will have already noted at least two areas of difference. To begin with, Habermas's focus is exclusively on crises of legitimacy that afflict social systems, particularly that of 'advanced capitalism'. This is not just an issue of concentration, but flows 
directly from how Habermas understands the coherence of social systems. Crises of legitimacy operating below the systemic level — such as those afflicting individuals, states, or particular institutions - are important only insofar as they articulate broader systemic crises of legitimacy. Our difference here is of an analytical rather than theoretical nature. The present international system is reportedly afflicted by multiple crises of legitimacy, and our preference is to (a) examine these on their merits, and (b) leave open for exploration the question of how crises afflicting particular actors, states, or institutions relate to existing or immanent systemic crises. Second, Habermas comes very close to defining crises as the terminal endpoints of social systems, moments in which arresting a 'legitimation deficit' is 'not possible by administrative means' $(1973,47)$. While this is consistent with the Marxist understanding of crisis (qua economic crisis), as explained above, it reduces the concept of crisis to a synonym for collapse, and runs counter to much conventional usage that speaks of crises of legitimacy that have been arrested.

Two important questions about international crises of legitimacy remain. The first is temporal. Can international crises of legitimacy extend over long periods of time, or must they be momentous in a temporal as well as developmental sense? The term 'crisis' certainly implies the former, suggesting a critical intensification of social forces that at once contrasts with prior conditions of equilibrium and anticipates immanent collapse. Yet historically crises of legitimacy have varied temporally. Some have been chronologically confined, with an actor or institution experiencing a dramatic collapse in social support leading to equally dramatic disempowerment. The crisis of legitimacy that ended the Nixon presidency is a case in point. Other crises have been more extended, however, unfolding over decades, even centuries, particularly when they have afflicted international institutions or orders, such as Europe's absolutist system of states. It appears, therefore, that when we say that a crisis involves an intensification of social forces, we are using the term 'intensification' first and foremost in a developmental not a temporal sense.

Crises of legitimacy that are temporally extended tend to be chronic, whereas crises of a more immediate nature tend to be acute. Chronic crises are those in which legitimacy deficits remain severe, but where the compensatory use of material inducements, or short-term legitimation strategies (such as Falklandstype military adventures), stave off disempowerment without recalibrating the social bases of legitimacy. Acute crises are those in which all viable options of material compensation have been exhausted (or do not exist), and where disempowerment is immanent unless the social bases of legitimacy are reconstituted. Implied here is the proposition that the use of coercion or bribery to compensate for legitimacy deficits is usually a tenuous solution, containing a crisis but seldom extinguishing it. As Edmund Burke famously wrote, 'the use of force is but temporary. It may subdue for a moment, but it 
does not remove the necessity of subduing again; and a nation is not governed, which is to be perpetually conquered' (Burke, 1908, 131). As we saw earlier, legitimacy supplies a number of vital ingredients of stable rule. Legitimate actors or institutions can draw upon, or be sustained by, wellsprings of voluntarism that encourage active support, simple compliance, and lower levels of opposition, reducing the costs of coercion and bribery. And because such voluntarism derives from actors' interpretations of social norms, which by definition prescribe forms of agency or action over time, it is conducive to stable forms of rule. Countering a crisis of legitimacy with coercion or bribery can bolster flagging social power, but it neither cancels the legitimacy deficit nor generates the voluntarism conducive to stable rule.

The second question concerns the issue of consciousness. Do social actors who are themselves afflicted by crises of legitimacy, or whose institutions are so afflicted, need to be aware of this for crises of legitimacy to exist? Because crises of legitimacy are inextricably linked to a decline in, or a failure to accrue, social recognition, they are necessarily dependent upon the changing consciousness of social actors. As Habermas observed, 'only when members of a society experience structural alterations as critical for continued existence and feel their social identity threatened can we speak of crises' $(1973,3)$. This does not mean, however, that actors afflicted by crises of legitimacy presidents, secretary generals, governments, or bureaucrats who maintain institutions - need be aware that they are experiencing a legitimation crisis, or that other social actors have to recognize an actor's or institution's flagging support as a crisis of legitimacy, per se. There have been many examples of actors stubbornly refusing to admit that legitimacy contributes to their social power, or blindly imagining that their social support exceeds what they actually command, or mistakenly thinking that their legitimacy rests on one foundation where in fact it rests on another. Yet the crises of legitimacy they ultimately experienced were real. What matters, it seems, is that consciousness, in the form of broad social perception of power without right, is essential to crises of legitimacy. But consciousness, in the form of a power-aspirant's understanding of his or her own illegitimacy, is not essential, even if it is characteristic of particular crises.

\section{The Question of Resolution}

Beyond the issue of what constitutes an international crisis of legitimacy, and the question of which legitimation crises afflict contemporary international relations, we are concerned here with the problem of resolution. What does it mean to 'resolve' an international crisis of legitimacy, and which of the contemporary legitimation crises are amenable to resolution? The remainder of 
this article takes up the first, more conceptual of these questions, while the second, more empirical question is addressed by our contributors.

The prima facie case for considering the question of resolution lies in the connection between legitimacy and international stability. As we have seen, when we say that an actor, institution, or order commands legitimacy, we are saying that its power (qua practical capacity) is recognized as rightful by social actors within its realm of political action. Legitimacy is valuable because with recognition comes voluntary compliance, and with voluntary compliance comes stable rule, characterized by comparatively lower levels of coercion and conflict. Because of this, scholars have repeatedly observed the contribution legitimacy makes to multiple dimensions of international stability. At the broadest level, it is often argued that international orders that enjoy high levels of legitimacy — where there is broad agreement on norms governing membership, procedure, and substantive values - also enjoy high levels of stability. At a more intermediate level, the legitimacy of international institutions is generally considered crucial to their political capacity. And at the level of state power in international relations, scholars have frequently argued that the critical difference been a dominant state and a hegemon is that the latter's power rests as much on legitimacy as material resources, and (bringing the story full circle) it is this quality of legitimacy that makes hegemony, and not domination, conducive to the stability of an international order. Crises of legitimacy are thus likely to be potent sources of international instability and disorder, especially if they afflict the constitutional and fundamental institutions of an international society, or the power of the principal states and other actors. It follows that asking how such crises can be resolved is a question of some importance to the maintenance of international peace and stability.

The concept of 'resolution' has been most thoroughly considered by theorists of conflict resolution. In general parlance, conflicts can be 'resolved' in any manner of ways. At one extreme, they can be resolved by letting the conflicting parties fight it out until one prevails. At the opposite extreme, they can be resolved by the parties reaching an uncoerced accommodation that respects and meets the concerns of each protagonist. In this general usage, 'resolution' simply means conclusion or ending. Theorists of conflict resolution use the term in a far more restricted sense than this one, though. A conflict is not considered resolved if one party prevails over another by force of arms, as in all likelihood the roots of the conflict will persist. Similarly, a conflict is described as settled but not resolved if it is coerced by an interested third party, as it may be based on a compromise that the conflicted parties would not have accepted if they had had the resources to resist. A conflict is said to be resolved only if a solution to a dispute is found that is acceptable to all parties, that concurs with their primary interests (even if these interests have been redefined through the 
process of negotiation), and that will not be vulnerable to repudiation subsequently. As Anthony de Reuck puts it, 'Resolution removes the very ground of dispute by eliminating or transforming the conflict situation' (de Reuck, 1984, 98). To resolve a conflict, therefore, is more than just quieting the protagonists; it is quieting them by negotiating away the underlying sources of the contestation. 'Resolve' here means more than to end; it means to end through change and transformation.

At first glance this conception of resolution would seem ill-suited to crises of legitimacy. For one thing, it implies a type of social conflict that differs structurally from most legitimation crises. The archetypal conflict resolution 'conflict' involves two or more atomistic actors, with strongly held preferences that they are determined to advance, and with the deep-seated belief that they are engaged in a zero-sum competition, in which a gain for one is a loss for another. International crises of legitimacy are types of conflict, but they generally take a different form. First, not all crises of legitimacy involve atomistic actors - as we have seen, international institutions and orders can experience legitimation crises, and while their critics and defenders might be fruitfully portrayed as atomistic actors, the fact that an institution is the subject of the crisis differentiates it from the standard conflict resolution model. Second, even when an international crisis of legitimacy appears to be between atomistic actors, it will necessarily have a normative dimension lacking in many other conflicts. When a society of states decides that a particular kind of polity is illegitimate and unworthy of sovereign recognition, it is sowing the seeds of a conflict that is inherently normative, concerned as it is with rightful membership. While there is a strand of conflict resolution theory that sees all conflicts as subjective, and hence normative, the predominant approach tends to objectify actors' interests, and to see the process of conflict resolution to be in part about bringing protagonists to understand their real interests.

These differences aside, though, the conflict resolution conception of 'resolution' is helpful to our task in one crucial respect. As we have seen, crises of legitimacy occur when an actor's or institution's level of social support drops to the point where its power can be sustained only by reconstituting the social bases of its legitimacy or by investing more heavily in material sources of power and their coercive applications. Following conflict resolution theorists (and the discussion in the previous section), we can reasonably exclude the second of these techniques as a form of resolution, as the power in question remains illegitimate even if it can be sustained. When we speak of resolving crises of legitimacy we are thus in the realm of the reconstitution of the social bases of power, and it is here that the conflict resolution notion of resolution is helpful. For an actor or institution to be judged legitimate, its identity, interests, or practices must resonate with values considered normative by other actors within their realm of political action. This process of legitimation is 
inherently political, as it involves the complex interplay of idiographic, purposive, ethical, and instrumental goals and practices (Reus-Smit, 2004, 24 29 ). But it is also inherently social, in the sense of involving interaction, communication, and accommodation.

Actors seeking legitimacy make legitimation claims that appeal to particular social values, actors whose support is desired make their own legitimation claims (appealing to the same or different values, with the same or different interpretations), and through this whole process the architecture of social norms is constituted and reconstituted. An actor's legitimacy is only established and maintained when its self-representations and institutional interpretations resonate with the normative expectations of other actors. Crises of legitimacy are only resolved, therefore, when these are reconciled, when the discordance that has eroded social recognition is overcome. While the archetypical conflict resolution conflict takes a different form from most crises of legitimacy, this resolution is akin to that described by conflict resolution theorists. Their archetypical conflicts are resolved through the communicative clarification or reconstitution of the parties' identities, interests, or practices, so that they come to see these as mutually compatible not incompatible, as neutral or positive-sum not zero-sum. Crises of legitimacy are resolved through a similar process of communicative clarification or reconstitution, this time between the representations and interpretations of the actor in crisis, the expectations of other actors, and the communicatively constituted norms of the social order.

Bringing these threads together, we can define the resolution of international crises of legitimacy in the following way. An international crisis of legitimacy occurs when an actor or institution's level of social support declines to the point where its power can only be sustained through the recalibration of its legitimacy or the compensatory use of material inducements. Legitimation crises can be resolved only through recalibration, which necessarily involves the communicative reconciliation of the actor's or institution's social identity, interests, or practices with the normative expectations of other actors within its realm of political action. This process of reconciliation necessarily involves interpretative argument over the nature and meaning of applicable social norms. A crisis can be said to be resolved when the actor or institution commands sufficient legitimacy within its realm of political action for it to achieve its objectives, or fulfil its mandate, through rightful licence and voluntary compliance first, and material inducement and coercion second.

If the relationship between legitimacy and international order provides the prima facie case for taking the issue of resolution seriously, the vexed relationship between justice, legitimacy and international order greatly complicates this issue. While international order may be served by minimizing crises of legitimacy, and by resolving those that emerge, justice may not. Take, 
for instance, the case of American hegemony. What if sustaining American hegemony contributes to international order but comes at great costs to human justice? What would be the ethics of resolving an American international crisis of legitimacy if this were the trade-off? Superficially, this looks like the perennial tension between order and justice, in which the practices required to sustain order compromise justice, and the pursuit of justice weakens the foundations of order. Yet the fact that we are talking about a crisis of legitimacy disturbs the established rituals of the order-justice debate. Resolving a hegemon's crisis of legitimacy would necessarily involve adjusting the hegemon's social identity, interests, and practices to the intersubjective structures of the international society and to the normative expectations of other actors, and there is no a priori reason why the values that define these structures and expectations should be limited to the realm of order as opposed to justice. Order may well depend upon sustaining legitimate hegemonic power, but re-establishing a hegemon's legitimacy may in turn depend upon the hegemon serving, and being seen to serve, justice as well as order. Whether this turns out to be the case is an empirical question, dependent upon the relationship between international and world society, the nature of prevailing international norms, and the available structures and technologies of communication. But theoretically, at least, exploring the resolution of international crises of legitimacy such as this is not anathema to considerations of justice, as processes of legitimation admit multiple values.

\section{Conclusion}

Jean-Jacques Rousseau famously wrote that 'The strongest man is never strong enough to be master all the time, unless he transforms force into right and obedience into duty' (Rousseau, 1968, 52). The leader who achieves this transformation can be said to command legitimacy, and the one who fails to be suffering a crisis of legitimacy, a crisis as detrimental to power as material decline. This special issue is about international crises of legitimacy - how we define them, how we identify them, and how we resolve them. This article has laid the conceptual foundations for the project, setting out a common set of terms and the theoretical reasoning that undergirds them. The task of identifying and analysing those crises of legitimacy that beset the contemporary international system falls now to our other contributors, who also have the task of exploring the possibility and desirability of resolving these crises. Their articles tackle everything from American power and the international financial institutions, to the human rights regime and the UN Security Council. In the concluding article, Ian Clark draws together the insights of these contributions, and outlines the project's principal conclusions. 


\section{Notes}

1 I use the term 'rightful' broadly. To judge something rightful is to give it normative sanction, to accept it on the grounds that it concurs with one's sense of appropriateness, which is in turn grounded in the social norms, values, and beliefs one embraces.

2 These two modes of adaptation may not be equally available to actors and institutions. It makes sense to speak of actors having (or not having) the material resources needed to offset legitimacy deficits, but it does not always make sense to speak of institutions in this way. Institutions with strong organizational dimensions (like the World Bank or the WTO) sometimes command these resources and have the agential qualities required to deploy them, but institutions without such organizational features (such as the Kyoto Protocol) generally lack these capacities for material coercion or cooption. If such an institution suffers a crisis of legitimacy, the option of material adaptation is limited to the willingness of interested actors to deploy material resources to attain compliance with the institutions norms, rules, and principles.

\section{References}

Bukovansky, M. (2002) Legitimacy and Power Politics, Princeton: Princeton University Press.

Burke, E. (1908) 'On Conciliation with the Colonies', in edited by Ernest Rhys (ed.) Speeches and Letters on American Affairs, London: J.M. Dent and Sons, pp. 76-141.

Clark, I. (2005) Legitimacy in International Society, Oxford: Oxford University Press.

Claude Jr, I.L. (1966) 'Collective Legitimation as a Political Function of the United Nations', International Organization 20(3): 367-369.

Coicaud, J.-M. (2002) Legitimacy and Politics: A Contribution to the Study of Political Right and Political Responsibility, Cambridge: Cambridge University Press.

de Reuck, A. (1984) 'The Logic of Conflict: Its Origin, Development and Resolution', in M. Banks (ed.) Conflict in World Society, Brighton: Wheatsheaf Books, pp. 96-111.

Habermas, J. (1973) Legitimation Crisis, Boston: Beacon Press.

Nye, J.S. (2002) The Paradox of American Power, Oxford: Oxford University Press.

Reus-Smit, C. (1999) The Moral Purpose of the State, Princeton: Princeton University Press.

Reus-Smit, C. (2004) 'The Politics of International Law', in C. Reus-Smit (ed.) The Politics of International Law, Cambridge: Cambridge University Press, pp. 14-44.

Rousseau, J.-J. (1968) The Social Contract, Harmondsworth: Penguin.

Sahlins, M. (1976) Culture and Practical Reason, Chicago: University of Chicago Press.

Suchman, M.C. (1995) 'Managing Legitimacy: Strategic and Institutional Approaches', Academy of Management Review 20(3): 571-610.

Waltz, K. (1979) Theory of International Politics, New York: Random House.

Weber, M. (1957) The Theory of Social and Economic Organization, New York: Free Press.

Wendt, A. (1999) Social Theory of International Politics, Cambridge: Cambridge University Press. 